\title{
Processos de globalização e problemas emergentes: implicações para o Serviço Social contemporâneo*
}

\author{
Processes of globalization and emerging Issues: \\ implications for the contemporary Social Services
}

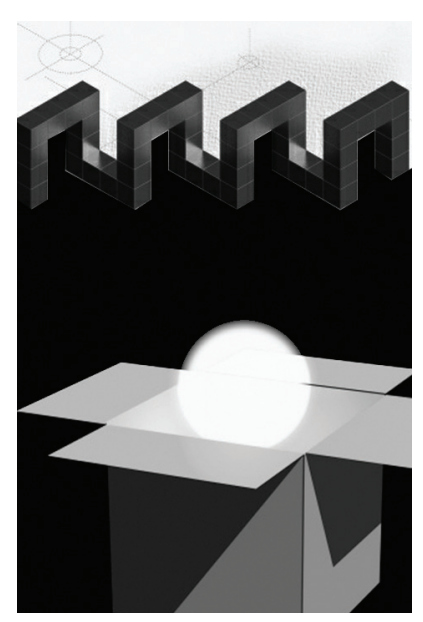

Nélson Alves Ramalho**

Resumo: O presente artigo aborda o desenvolvimento dos processos de globalização, promovendo uma reflexão sobre as transformações do mundo actual e os seus impactos nas sociedades contemporâneas. A temática tem como ponto de partida a análise dos problemas emergentes numa sociedade de risco e as suas implicações nas transformações do Serviço Social, tendo em vista a exploração dos desafios que se colocam aos assistentes sociais face à crise de modernidade e à necessidade de repensar a profissão.

Palavras-chave: Globalização. Sociedade de risco. Crise da modernidade. Serviço Social.

\begin{abstract}
This article presents a discussion about the development of the processes of globalization, as well as a reflection on the transformations in the world nowadays and their impacts on the contemporary society. The first aspect to be dealt with is the analysis of the emerging problems in a risky society and their implications in the transformation of the Social Services, as the social workers are challenged to face the modernity crisis and to think over the profession.
\end{abstract}

Keywords: Globalization. Risky society. Modernity crisis. Social Services.

* Este artigo corresponde a um relatório de pesquisa.

** Doutorando do V Programa de Doutoramento da Universidade Católica Portuguesa de Lisboa, Portugal. Investigador do Centro de Estudos de Serviço Social e Sociologia (CESSS) da Faculdade de Ciências Humanas da Universidade Católica Portuguesa de Lisboa.E-mail: nelson.ramalho81@gmail.com. 


\section{Introdução}

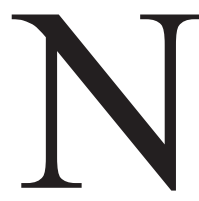

as últimas décadas tem-se tomado maior consciência do mundo como um sistema global e interdependente. Este fenómeno, denominado por "globalização", constitui-se, em si mesmo, como um acontecimento de uma nova e complexa história da humanidade. A globalização é um dos termos mais difundidos e discutidos para explicar as transformações das sociedades actuais. Embora seja assumida a sua importância, parte dos discursos acerca do seu conceito não são consensuais, outros são atravessados por simplificações, exageros, imprecisões e, muitas vezes, o seu uso indiscriminado e pouco cuidado convida à confusão conceptual.

Giddens (2006) afirma existirem duas principais visões da globalização. Uma, caracterizada pelos "cépticos", cujos autores tratam o fenómeno como sendo uma questão de retórica ou mesmo um mito, alegando a inexistência da globalização por considerarem que "a economia global não é assim tão diferente da que existia em períodos antecedentes. O mundo continua o mesmo, está assim desde há muitos anos" (p. 20). Outros, "os radicais", assumem uma visão diametralmente oposta, sustentando que estamos impelidos rumo a um mercado global, cujo período não se centra no futuro, mas sim no tempo presente, uma vez que os efeitos da globalização podem ser sentidos em qualquer parte do mundo, no aqui e no agora.

Ambas as visões acabam por conceber o fenómeno da globalização e as suas implicações quase, exclusivamente, como "um fenómeno de natureza económica" (Giddens, 2006, p. 22). Assim sendo, torna-se redutor explicar a globalização numa vertente monocausal, uma vez que estamos perante um fenómeno multifacetado com dimensões económicas, sociais, geopolíticas, demográficas, culturais, psicológicas, científico-tecnológicas, religiosas e jurídicas ligadas entre si e de forma complexa, ancorado nas novas tecnologias de informação e comunicação (Giddens, 2006; Santos, 2005; Steger, 2006). Desta forma, compreende-se que a globalização "não é um processo simples, é uma rede complexa de processos" (Giddens, 2006, p. 24) que "criam, multiplicam, estendem e intensificam interdependências e intercâmbios à escala mundial enquanto, ao mesmo tempo, encorajam nas pessoas uma consequência crescente de ligações cada vez mais profundas entre o local e o longínquo" (Steger, 2006, p. 22). Para esses autores, aumentam as evidências que os levam a crer numa rápida intensificação das 
relações sociais à escala mundial, afastando-os da visão de alguns cépticos que chegam a negar, completamente, a sua existência.

A presente reflexão não visa apontar soluções, mas sim procurar alguns contributos para a compreensão deste fenómeno, os seus impactos na realidade social e os desafios que se impõem ao Serviço Social contemporâneo.

\section{Globalização: um fenómeno contemporâneo?}

Muito embora a globalização represente um grande marco histórico nas sociedades actuais, a tendência para ampliação dos horizontes humanos é bastante antiga. Tão antiga como a própria humanidade e quanto se estiver interessado em conhecer a história das migrações humanas, das redes sociais e das inovações tecnológicas (Campbell, Mackinnon e Stevens, 2010).

Para explicar a raiz dos processos da globalização, alguns autores, como Steger (2006) reportam-se a períodos pré-históricos (10.000 a.C.-3.500 a.C.) e a períodos pré-modernos (3.500 a.C.-1.500 d.C.). ${ }^{1}$ Outros, como Silva (2008) e Warnier (2002), abordam três grandes períodos do processo de globalização.

O primeiro periodo, marcado pelo processo expansionista dos descobrimentos por via maritimado, século XV, é caracterizado pela conquista, exploração e colonização das terras além-mar e confronto com os novos povos. Para além da conquista física de aproximação dos povos e de uma profunda consciência de um mundo que se tornou "mais pequeno", a expansão marítima teve como consequência a constituição de rotas internacionais que puseram, em relação directa, as distintas economias espalhadas por todo o mundo. A economia foi, assim, a primeira área em que se acentuou este fenómeno, transformando o globo num amplo mercado de capitais.

Para o surgimento do segundo período da globalização contribuíram, no século XVIII, a Revolução Francesa e a Revolução Industrial. Influenciadas

1. Para Steger, a globalização poderá remontar ao periodo pré-histórico, no qual um pequeno grupo de caçadores hominídeos africanos conseguiram deslocar-se até o extremo meridional da América do Sul. O periodo pré-moderno é caracterizado pela invenção da escrita (na Mesopotâmia, Egipto e China) e a invenção da roda, que impulsionou a criação dos carros de atracção animal e das estradas que estimularam o transporte de pessoas e mercadorias com maior rapidez. Neste período surgiu, também, a engenharia hidráulica, a pólvora, o papel e a impressão, os sistemas de irrigação, as rotas comerciais da seda, entre outros acontecimentos (Steger, 2006, p. 28-32). 
pelos princípios iluministas e da substituição das ferramentas pelas máquinas, ajudaram a consolidar a globalização do capitalismo e as teorias económicas liberalistas. A Revolução Industrial veio permitir a formação de uma nova classe social - o proletariado - composta, na sua essência, por pessoas que vinham dos campos para se fixarem nas cidades à procura de trabalho, e a sua imigração massiva contribuiu para o crescimento dos aglomerados urbanos da altura, alterando as formas de vida social. Quanto mais o processo de industrialização se acentuou, maiores disparidades socioeconómicas emergiam. A partir daqui, criaram-se duas e diferentes grandes forças: por um lado, a riqueza mercantil e o capitalismo industrial e financeiro e, por outro, uma massa assalariada que, sem recursos, dispunha apenas da sua capacidade de trabalho, ficando sujeitos a situações de extrema vulnerabilidade. Esta desigualdade social é tratada como a "questão social". ${ }^{2} \mathrm{Na}$ verdade, foi também nesse período que as políticas liberalistas contribuíram para que capital e mercadorias fluíssem através das fronteiras, de uma forma relativamente livre, aumentando assim o volume do comércio mundial.

O século XX correspondeu ao terceiro período da globalização. A manutenção do processo de industrialização e a consequente estruturação das cidades exigiram a utilização de novas fontes de energia, como a electricidade e o petróleo, bem como a inovação dos meios de transporte — com a construção de caminhos de ferro, a navegação mercantilizada, os transportes aéreos - complementadas pelo rápido desenvolvimento da ciência e das tecnologias de informação e comunicação.

Este processo de inovação, que assumiu contornos mais nítidos a partir do final da II Guerra Mundial, e que se intensificou no anos 1970-80, permitiu estender as relações sociais, comprimir o tempo e o espaço-território e determinar uma crescente sensação, cada vez mais real, de um mundo que "encolheu" de forma rápida. A globalização constituiu-se, assim, numa ruptura na história da civilização, marcada pela reconfiguração do espaço social que se expressa na supraterritorialidade ${ }^{3}$ dos vários aspectos da vida social, sejam eles políticos, sociais, económicos ou culturais (Scholte, 2000).

2. É neste contexto que surgem as primeiras práticas que fundaram o Serviço Social enquanto profissão de defesa da justiça social

3. Scholte (2000) utiliza este termo para designar que o espaço social moderno, onde se processa a globalização, envolve relações sociais que se estabelecem para além da limitação físico-geográfica de um 
A globalização possibilitou "vencer os últimos obstáculos geográficos que restavam ao estabelecimento de uma genuína infraestrutura global" (Steger, 2006, p. 40). Hoje em dia, o mundo ruma a uma nova direcção: não mais nacional, e sim global. Vive-se uma era cuja dinâmica global está cada vez mais presente nas nossas vidas, afectando-nos individualmente e de forma indiscriminada. Giddens (2006, p. 19) afirma que:

vivemos num mundo de transformações, que afectam quase tudo o que fazemos. Para o melhor e para o pior, estamos a ser empurrados para uma ordem global que ainda não compreendemos na sua totalidade, mas cujos efeitos já se fazem sentir em nós.

\section{As dimensões dos processos da globalização: seus impactos e problemas emergentes nas sociedades contemporâneas}

Sabendo que a compreensão do processo da globalização, pelo seu carácter multifacetado, requer uma visão abrangente, analisar-se-ão algumas destas dimensões, tentando evitar o isolamento do fenómeno centrando-o apenas em determinados aspectos, procurando interpretá-lo de forma holística, estabelecendo relações necessárias.

Relativamente à dimensão económica, da globalização assiste-se, hoje, a uma transformação da realidade do mercado financeiro que é capaz de realizar transacções e investimentos comerciais de forma desvinculada a um espaço territorial, ligando os mercados e as economias do mundo inteiro através de estratégias económicas que são coordenadas supraterritorialmente (Scholte, 2000).

$\mathrm{Na}$ base dessa transformação da produção poder-se-á estabelecer uma primeira ligação à divisão do trabalho e da produção em massa, iniciadas com a Revolução Industrial. Uma segunda ligação, à conferência de Bretton Woods de $1^{\circ}$ de julho de 1944, realizada no final da II Guerra Mundial, cujos participantes concordaram em estabelecer regras obrigatórias às actividades econó-

território, envolvendo também, uma dimensão virtual espacial e temporal. Toma-se, em exemplo, a Internet, cuja tecnologia nos permite estabelecer contactos e conexões de uma parte do mundo para qualquer outra, em tempo real e de forma simultânea, comprimindo tempo e espaço. 
micas internacionais. Da conferência surgiram, também, a constituição de novas organizações económicas internacionais, perante as quais os Estados nacionais se regem, se orientam e adoptam regras e procedimentos mundiais comuns (Campbell, Mackinnon e Stevens, 2010; Steger, 2006). Actualmente, e numa terceira ligação, assiste-se à emergência da "nova divisão do trabalho", reinventada numa vertente de carácter internacional, iniciada por empresas transnacionais. Santos (2005, p. 35) refere-se a essas empresas como "os actores centrais da nova economia mundial", uma vez que é nelas que reside a grande concentração de poder económico. O crescimento destas empresas e a sua presença central, maioritariamente, em três forças (a América do Norte, a Europa e o Japão), formam três grandes capitalismos transnacionais, reflectindo relações de poder assimétricas entre Norte/Sul (Santos, 2005; Steger, 2006), na medida em que controlam grande parte dos mercados internacionais. ${ }^{4}$ É nessa linha de pensamento que Giddens (2006) considera, embora numa abordagem mais pessimista, que a globalização é um negócio económico dos países industrializados, em que os países do Sul e menos desenvolvidos têm um papel passivo, criando assim "um mundo de vencedores e vencidos, minorias que enriquecem rapidamente e maiorias condenadas a viver uma vida de miséria e desespero" (p. 26).

No entanto, abordar a globalização sem se analisar a dimensão política do processo pode tornar a discussão inconsistente e superficial. Santos (2005) considera que, actualmente, está embutida nos discursos políticos e na linguagem comum uma ideia falaciosa que leva a acreditar que a globalização "é um fenómeno linear, monolítico e inequívoco" e um processo "espontâneo, automático, inelutável e irresistível que se intensifica e avança numa lógica e numa dinâmica próprias suficientemente fortes para se imporem a qualquer interferência externa" (p. 56), ideia esta semelhante à visão e discursos dos "cépticos". Todavia, para o autor, a globalização não é mais do que o resultado conjunto de decisões políticas.

A criação e o aumento da importância de várias instituições supranacionais e intergovernamentais ${ }^{5}$ contribuíram para a regulação de uma ordem interna-

4. Das cem maiores economias mundiais, 51 são empresas transnacionais e apenas 49 são representadas por países (Steger, 2006).

5. Como o Fundo Monetário Internacional (FMI), o Banco Mundial (BM), a Organização Mundial do Comércio (OMC), a Organização das Nações Unidas (ONU), a Organização do Tratado Atlântico do Norte (Otan) e a Organização para a Cooperação e Desenvolvimento Económico (OCDE). 
cional e fortificação das relações entre Estados (Brum e Bedin, 2003; Campbell, Mackinnon e Stevens, 2010; Santos, 2005; Steger, 2006; Yáñez, 1997), favorecendo uma extensão tentacular das actividades políticas para além das fronteiras nacionais, transformando os diferentes Estados numa rede de interdependência política cuja "pressão internacional tem sido, tradicionalmente, na uniformização e na normalização" (Santos, 2005, p. 43). Tal facto tem sido capaz de afrontar e desafiar a própria soberania dos sistemas de Estado-nação, com a perda da sua centralidade tradicional e o seu enfraquecimento na economia global (Bauman, 1999; Santos, 2005; Steger, 2006). A dúvida instala-se: o resultado desses processos tende a rumar a uma governação mundial? A resposta torna-se dúbia. Para Bauman (1999), tendemos, antes, a uma "desordem mundial". ${ }^{6}$

A relação capitalista, vinculada nos processos de globalização, é considerada como uma relação desigual no poder e na distribuição das riquezas, não unicamente na dimensão económica ou política, mas também na esfera social (Silva, 2008; Santos, 2005). As novas desigualdades, retratadas nos discursos sobre a "nova questão social" moderna (Castel, 1997; Paugam, 2003; Rosanvallon, 1995), têm a sua origem numa "nova divisão da estrutura de classes", consequente da "nova divisão do trabalho". A emergência de uma classe elitista de burgueses executivos composta por ramos locais (formados por directores de empresas, líderes políticos e profissionais influentes) e internacionais (que englobam gestores de empresas multinacionais e dirigentes de instituições financeiras internacionais) vem contrastar, fortemente, com o surgimento dos "novos pobres" que se encontram numa estreita relação com a funcionalidade dos mercados, o desemprego e a precarização do trabalho.

Se, inicialmente, no contexto da industrialização, a questão social se centrava num problema de justiça social dos trabalhadores assalariados explorados e em como transformar esses actores sociais, subordinados e dependentes, em sujeitos sociais de direitos, agora a questão consiste em como fazer face às ameaças que abrangem toda a classe social trabalhadora moderna, que se confronta com a eminência de perder os seus empregos e com a instabilidade e

6. Bauman (1999) defende que a forte tendência de eliminação das funções do Estado-nação poderá, eventualmente, levar a uma desordem mundial, na medida que não existe ninguém no comando da situação e do controlo e, por isso, questiona o próprio destino da humanidade. A desordem retracta a falta de definição de rumos a serem tomados. 
precariedade das suas situações profissionais. Silva (2008, p. 152) sublinha que essas "desigualdades estruturais estão hoje fortemente agravadas em detrimento dos salários e em proveito dos lucros".

O Programa das Nações Unidas para o Desenvolvimento (PNUD) de 2010 e, especialmente, o Relatório do Desenvolvimento do Banco Mundial (2010) refere que, nos últimos anos - como resultado do processo de crise que, presentemente, os mercados internacionais estão a viver - 34 milhões de pessoas perderam os seus empregos e outros 64 milhões atingiram situações de extrema pobreza. ${ }^{7}$ Muito embora sejam evidentes grandes avanços societais ao longo das últimas décadas, ${ }^{8}$ a avaliação não é considerada inteiramente positiva, uma vez que se tem assistido a um aumento das disparidades sociais e a um fosso maior entre os países desenvolvidos e os em vias de desenvolvimento (PNUD, 1999; PNUD, 2001; PNUD, 2010).

Estes dados mostram-nos que os padrões de crescimento têm sido extremamente desiguais, porque as oportunidades e as recompensas da globalização distribuem-se, também, de forma desigual. O poder e a riqueza estão, agora, concentrados, num grupo seleccionado de pessoas, regiões e empresas (Steger, 2006; PNUD, 1999; PNUD, 2001; PNUD, 2010).

Ao longo do desenvolvimento dos processos de globalização, a dimensão científico-tecnológica esteve, também, sempre presente. É inegável que sem o seu avanço, nada do que hoje experienciamos nas nossas vidas seria possível. No entanto, alguns autores consideram que as primeiras visões dessa dimensão foram sendo construídas sob um ideário prometeico, em que o seu crescimento acabaria por impulsionar a elevação do nível de bem-estar, beneficiar toda a humanidade e trazer resultados altamente previsíveis (Coutinho, 2002; Garcia, 2003; Habermas, 2009; Martins e Garcia, 2006). A tecnologia apareceu imersa nesse ideário, de tal forma que se pensava que poderia vir a "alterar o mundo, transformar os nossos empregos, revolucionar as nossas famílias e educar os nossos filhos [...] mudar os métodos agrícolas e médicos tradicionais, assim

7. Definida como viver com menos de USD 1,25 de rendimento por dia.

8. No relatório do PNUD (2010) é descrito estes avanços, ao nível do desenvolvimento das Nações: a maior parte das pessoas tem mais saúde, vidas mais longas, mais instrução, maior acesso a bens e serviços, maior riqueza e maior poder para eleger os seus líderes. Quase todos os países beneficiam desse progresso. Dos 135 países que compõem a amostra entre 1970 e 2010, com 92\% da população mundial, apenas três (República Democrática do Congo, a Zâmbia e o Zimbabué) têm um Índice de Desenvolvimento Humano (IDH) inferior ao de 1970 . 
como modificar os genes dos organismos vivos, talvez mesmo o organismo humano" (Winner, 2003, p. 79).

O papel crucial das tecnologias de informação e comunicação deverá ser, efectivamente, o de estimular o desenvolvimento económico e social dos países. Contudo, acerca disto, Castells (1999) refere que este aspecto pode tornar-se "uma espada de dois gumes", na medida em que, por um lado, essas tecnologias permitem que os países cresçam através da modernização de sistemas de produção competitivamente mais rápidos do que no passado, sendo uma ferramenta essencial no e para o desenvolvimento económico e bem-estar de cada economia. Por outro lado, as economias que se tornam incapazes de se adaptar aos novos sistemas tecnológicos tendem a tornar-se mais excluídas, porque dependem da capacidade do conjunto da sociedade para ser educada e ser capaz de assimilar o complexo processo de informação. Neste sentido, as regiões e as empresas que concentram a maior parte da produção e gestão dos sistemas avançados da tecnologia (grande parte centrados em países desenvolvidos) beneficiam e lucram ao importarem capital humano qualificado dos países e economias periféricas. Este fenómeno, denominado de "fuga de cérebros" e descrito no Relatório do PNUD (2001), acarreta, para os países exportadores, sérios riscos de permanecerem ainda mais à margem, uma vez que o crescimento de uma economia está intimamente relacionado com o nível do capital humano da mesma.

Nesta linha de pensamento, Amaro (2005), Garcia (2003) e Winner (2003) concebem o desenvolvimento tecnológico vinculado ao sistema político-empresarial. Como afirma Coutinho (2002, p. 214) "a ciência e técnica tornam-se, assim, facilmente, uma nova ideologia que legitima o poder político" e a organização socioeconómica. Habermas $(2009$, p. 72) designa esta interdependência como a "cientifização da técnica", significando com isto que, numa sociedade do capitalismo avançado, passa a acontecer uma marginalização da ética e dos valores e um predomínio da técnica, passando esta a desempenhar um papel ideológico e, por isso, legitimador da realidade.

No entanto, começam a surgir mudanças de paradigma face à ciência e à tecnologia. Paradigma este que, implicitamente, esteve alicerçado na inocência da própria ciência como sendo um processo inevitável, que continha sempre o caminho para o progresso. Presentemente tem surgido um novo paradigma que aceita a noção de que o progresso não é ilimitado porque "não concebe qualquer espaço à reflexão sobre o bem comum" (Winner, 2003, p. 84). Neste sentido, 
uma vez que a ciência e a tecnologia parecem já não estar postas ao serviço da humanidade numa proposta de felicidade, é necessário que, tal como Amaro (2005) refere, a sociedade possa, criticamente, reflectir sobre os bons e maus usos da inovação tecnológica e o sentido da finalidade que persegue, para potenciar a própria humanidade.

\section{Sociedades contemporâneas: sociedades de risco?}

Como observámos, esta rede complexa de processos e interdependências ocorrem da junção de vários factores, níveis e dimensões (Scholte, 2000; Steger, 2006). É nesse conjunto de "globalizações" e de relações sociais diferentes 9 que surgem conflitos e com eles vencedores e vencidos que podem, a longo prazo, ter impactos irreversíveis (Santos, 2005). Essa relação entre os processos de globalização e o surgimento e expansão de situações de risco social permite-nos observar que a globalização pode contribuir para limitar os seus contributos para um desenvolvimento humano sustentável.

A supressão da pobreza é um desses limites. Após anos de liberalização e desregulação do mercado mundial, não foi possível observar o seu fim. Pelo contrário, tais políticas têm promovido a "globalização da pobreza" (Chossudovsky, 1997). Associado a ela está, também, a questão do emprego. Segundo Amaro (2005), as actuais relações instáveis e precárias de trabalho, a expansão do desemprego e os baixos salários constituem uma limitação à acessibilidade dos consumos tradicionais, sendo difíceis ou impossíveis para uma parcela importante da população.

A junção da má qualidade de vida (em consequência da pobreza) e a falta de oportunidades conjugado com a difusão da "qualidade" nos países desenvolvidos através da globalização dos meios de informação e comunicação, fizeram impulsionar o crescimento massivo do fenómeno das migrações ${ }^{10}$ Aliado

9. Santos atribui à constelação desses conjuntos distintos de relações sociais, que originam diferentes fenómenos de globalização, a terminologia de "globalizações" usada no plural. Segundo ele, "não existe uma entidade única chamada globalização” (2005, p. 62).

10. Segundo dados da International Organization for Migration (IOM) de 2010, o número de migrantes cresceu de 150 milhões, em 2000, para 215 milhões, em 2010. Estima-se que em 2050 haja 405 milhões de migrantes como resultado do crescimento das disparidades demográficas, os efeitos das mudanças ambientais e a nova dinâmica política e económica global, a revolução tecnológica e as redes sociais. 
a esses problemas estão, também, o crescimento populacional, os conflitos étnicos e o renascimento da intolerância, o terrorismo e a insegurança social.

Há, também, as questões ambientais (Giddens, 2006) cujas sociedades contemporâneas tendem a ter dificuldades na resolução de problemas relacionados com as mudanças climáticas, a camada do ozono, a desertificação, a dependência do consumo de combustíveis não renováveis, a diminuição (com risco de perda) da diversidade biológica, a poluição transfronteiriça e a destruição dos recursos naturais. Há, ainda, as questões relacionadas com o progresso técnico moderno, nomeadamente, no nível das armas nucleares potencialmente destrutivas, dos organismos geneticamente modificados na agricultura e na alimentação e dos resíduos nucleares altamente radioactivos (Garcia, 2003; Jerónimo, 2006; Martins e Garcia, 2006; Winner, 2003).

Face a todas essas situações, confrontamo-nos perante questões éticas e inquietações no decurso da globalização: Será que o progresso alcançado conseguiu gerar um não progresso? Que rumos tomamos? Que limites são impostos ao avanço da ciência e da tecnologia? Que responsabilidades estão inerentes a todos esses "avanços" para que o planeta e as gerações futuras não sejam comprometidas? Será o homem secundarizado e visto como um meio para incrementar e alimentar o sistema capitalista ou deverá ser, antes, a centralidade no progresso da humanidade com vista à sua felicidade? Estamos perante a destituição de valores humanistas e de uma ética global?

Como abordam Hespanha e Carapinheiro (2001, p. 16), "muitos dos problemas não têm uma resposta organizada e é ainda o Estado nacional ou, na sua falta, as instituições locais quem se ocupa deles, mobilizando recursos e redes de solidariedade primárias". Face a essa realidade, cresce a pressão sobre os Estados-nação para que possam desenvolver políticas activas perante esses "novos problemas" quando, na realidade, não se deveria reivindicar uma intervenção supranacional capaz de resolver, ou minimizar substancialmente, os problemas localizados, uma vez que foram originados, na sua génese, pelos processos da globalização?

É nesta análise que se introduz o conceito de "sociedade de risco" (Beck, 1992). O autor atribui riscos ${ }^{11}$ de perigosidade globalizada imputados às deci-

11. A expansão do conceito de risco fez-se à custa de uma ausência de delimitação analítica clara entre "risco" e outras noções como "incerteza", "perigo" ou "ameaça". Abordar o conceito de risco é abordar, 
sões humanas, relações sociais, institucionais e dinâmicas deliberadas produzidas no desenvolvimento das sociedades modernas e que atingem, de forma indiscriminada, todos os países, classes sociais e com repercussões geracionais. De facto, para o autor, a "democratização dos riscos" não escolhe grupos específicos em termos de rendimento, prestígio ou poder para a difusão dos seus impactos. Esta falta de imunidade de todos face às ameaças globais fá-lo designar o conceito de "efeito de boomerang". Beck (1992) revela que estes novos riscos deixam, então, de poder ser pensados localmente e de forma circunscrita e ao, tendencialmente, democratizarem-se passam a assumir um carácter global, estendendo-se a todas as classes sociais, culturas, raças e nações. São, segundo ele, as ameaças ecológicas, sociais, políticas, económicas e individuais, anteriormente desconsideradas, que põem em risco a vida de todo o planeta.

Beck (1992) e Giddens (2006) argumentam que esses riscos são produtos humanamente fabricados no próprio conceito de desenvolvimento. ${ }^{12}$ Por um lado, o conhecimento técnico-científico permitiu controlar e minimizar alguns riscos, por outro, permitiu gerar novos e desconhecidos riscos com consequências globais. No entanto, essas novas formas de risco tornam-se de grande complexidade ao entendimento humano pelo seu desconhecimento sobre eles e pela falta de experiência no seu trato (Areosa, 2008).

Beck (1992) compreende que é na passagem e no confronto de paradigma da "sociedade industrial e de classes"13 (que tenta oferecer a resolução dos problemas da escassez, assegurando as necessidades básicas e a generalização do bem-estar e, com isso, o controlo da incerteza - através do desenvolvimento tecnológico) para a sociedade do risco ${ }^{14}$ (cuja modernidade trouxe o retorno das incertezas através de riscos produzidos pelo processo de desen-

necessariamente, os restantes conceitos. Desta forma, o conceito de risco remete-nos para cenários de probabilidade de ocorrência de eventos futuros (Giddens, 2006; Granjo, 2006; Jerónimo, 2006), o que permite que autores como Areosa (2008), Martins (1998, citado em Jerónimo, 2006) queiram antes falar em "sociedades de incerteza", na medida em que, não traduzindo uma visão errónea do conceito, transmitem a imprevisibilidade de o acontecimento ocorrer sabendo, no entanto, quais os potenciais efeitos que podem surgir.

12. É nesse contexto que ambos utilizam o conceito de "risco fabricado" que se diferencia do "risco externo" como sendo o risco proveniente da natureza externa como as más colheitas, inundações, pragas ou fomes. O "risco fabricado" refere-se ao risco causado pelo próprio impacto do desenvolvimento.

13. Também considerada como a "primeira modernidade".

14. Considerada como a "segunda modernidade". 
volvimento) que surge o conceito de "modernidade reflexiva". Esta noção de reflexividade acarreta o confronto com a nova identidade da sociedade moderna e o autoconfronto com as consequências que nela se fazem iminentemente sentir e a possibilidade de autodestruição. O agravamento desse risco social, traduzido nesta passagem de um período de certezas para um período de incertezas e imprevisibilidade, relaciona-se com uma menor capacidade institucional de resposta dos Estados-nação face a consequências inesperadas e indesejadas, à incapacidade de previsão, organização e controlo dos riscos emergentes do próprio processo de globalização (Areosa, 2008; Santos, 2005). É este o motivo para se considerar que o risco assumiu, nos dias de hoje, um carácter político, exigindo políticas públicas a serem formuladas por instituições internacionais com vista a uma "domesticação da incerteza" (Carapinheiro, 2005) e a uma "ordem mundial" (Bauman, 1999). Sobre este assunto, Areosa (2008) e Giddens (2006) acreditam que para enfrentar uma sociedade global de risco é necessário repensar a sociedade através de uma gestão global do risco.

Perante isso, que reconfigurações são necessárias para a possibilidade de condução de um novo sistema mundial? Perante esse período de transformação e de indefinição, Santos (2005) propõe, numa visão catastrófica e apocalíptica, a "teoria aberta à possibilidade de caos" (p. 62) ao pretender expressar a situação de bifurcação em que as sociedades modernas se encontram.

\section{Da crise da modernidade ao repensar das sociedades: transformações, desafios e implicações para o serviço social contemporâneo}

É inquestionável que a globalização trouxe avanços em vários segmentos da sociedade. Contudo, tais avanços permitiram a criação de uma ideologia dominante consolidada nas crenças do progresso prometido da globalização. Esta acabou por cinzelar o mundo e ter causado uma espécie de cegueira sobre as suas consequências, minimizando a importância de resposta aos problemas dela emergentes que se traduziram em disparidades na riqueza e no bem-estar, no desemprego estrutural, na insegurança humana, na degradação da natureza e no enfraquecimento dos Estados-nação. É neste sentido que alguns pensadores atrevem-se a chamar aos sinais do paradigma dominante instalado de "crise da modernidade" (Giddens, 2006; Santos, 2005; Steger, 2006). 
Todas essas consequências favoreceram questionamentos éticos, políticos, sociais, científicos por parte de movimentos de opositores ideológicos ${ }^{15}$ que acreditam que a ideia de inexistência de alternativas à globalização ignora qualquer capacidade para a organização humana. Confrontamo-nos, hoje, com a emergência e a instauração desses movimentos que reflectem uma tendência para desafiar a ordem mundial preestabelecida nas suas reivindicações de uma maior consciência das estratégias neoliberalistas e a necessidade deencontrar um novo paradigma alternativo, mais democráticas, justo e equitativo a favor da humanidade.

Todavia, mesmo que estas contraforças da globalização possam impulsionar uma maior consciência do rumo a tomar pela sociedade, torna-se improvável que um conjunto de processos sociais tão poderosos como a globalização, possa ter termo ou desacelerar (Steger, 2006). Santos (2005, p. 76) chega mesmo a afirmar que a criação de uma política transnacional é, por agora, meramente simbólica "uma vez que está por concretizar (ou sequer imaginar)" e que todos esses movimentos que irrompem em diferentes partes do mundo "são, por vezes, vistos como sinais de uma sociedade civil e política global apenas emergente". As resistências e os conflitos à volta desses movimentos fazem prova que a globalização não é mais do que um campo de lutas transnacionais onde quem tem poder, segundo a perspectiva foucauliana $(1977,1982)$, exerce, influencia, domina e fá-lo sentir.

É nessa disputa de forças que se distingue a globalização "de cima para baixo" ou hegemónica, e globalização de "baixo para cima" ou contra-hegemónica (Santos, 2005; Steger, 2006). É na constituição de grupos de resistência e contra-hegemónicos que se centra a luta desses dois campos de forças em acção. Face a isto, torna-se interessante colocar em debate de que maneira o Serviço Social poderá ser parte constituinte de um movimento de resistência do processo da globalização? De que forma os movimentos de opositores ideológicos à

15. Santos $(2005$, p. 73$)$ conceitua esse tipo de movimento de resistência como "cosmopolitismo" onde nele se incluem uma heterogeneidade de movimentos e organizações. Steger (2006) aborda esses movimentos de resistência como "movimentos antiglobalização" que poderão ser divididos em dois campos ideológicos: a) os proteccionistas particularistas — grupos que responsabilizam a globalização pelos problemas que afectam os países e tentam proteger os seus modos de vida tradicionais e; b) os proteccionistas universalistas - grupos com uma vertente política progressista, guiados por ideais de igualdade e justiça social para todos (e não apenas para os cidadãos do seu país) e que tentam construir uma ordem internacional baseada na redistribuição da riqueza. 
"globalização hegemónica" poderão abalar, mesmo que ainda de forma muito emergente e, por vezes, politicamente inconstante, as crenças dessa legitimidade a que a globalização poderá estar alicerçada?

Na abordagem de Castells (1999) acerca da redefinição do desenvolvimento social e de uma possível transformação social de mentalidades, o mesmo garante que o verdadeiro obstáculo ao desenvolvimento é, e continua a ser, eminentemente político. Na possibilidade de se impedirem confrontos violentos entre quem, politicamente, aposta numa globalização hegemónica e quem se posiciona enquanto opositor a essa forma de desenvolvimento, urge, desta visão, a importância de se tentar definir e implementar um novo acordo global (Castells, 1999, PNUD, 2010; Steger, 2006, p. 135).

\subsection{As transformaç̃oes profissionais do Serviço Social}

Todas essas profundas transformações no mundo contemporâneo exigem um repensar do Serviço Social com vista à sua recriação e, consequentemente, ao seu reposicionamento na sociedade (Dominelli, 2004; Iamamoto, 1996; Lorenz, 2005; Midgley, 2001; Mouro, 2009; Webb, 2003). Para Dominelli (2004, p. 16), os "assistentes sociais necessitam de redefinir a profissão, repensá-la e desenvolver novos paradigmas para a prática". Perante isto, que desafios se impõem ao Serviço Social e qual o papel face à presente realidade social? De que forma poderá contribuir para o estabelecimento de uma política alternativa à vigente? Que mudanças o próprio Serviço Social sofreu no decurso dos processos da globalização e que alterações se preveem? Estaremos ou deveremos caminhar para um Serviço Social internacional?

Muito embora tenha surgido nos últimos anos literatura científica que aponte para a presença de um Serviço Social internacional, colocá-lo como profissão de direitos humanos a uma escala global e a ambição de construir um projecto global para o Serviço Social é ainda um ensaio (Midgley, 2001; Payne e Askeland, 2008; Webb, 2003). Apesar da expansão do número de escolas e profissionais de Serviço Social por todo mundo (Midgley, 2001); da realização de actividades laborais desenvolvidas por assistentes sociais em instituições e organizações internacionais, da participação em visitas e conferências internacionais e da presença de organizações que sugerem a existência de um Serviço Social internacional, desenvolvidas pela International Federation of 
Social Work (ISFW) e International Association of Schools of Social Work (IASSW), o facto é que "poucas pessoas estão activamente envolvidas na prática do Serviço Social Internacional" (Payne e Askeland, 2008, p. 6), confluindo condições várias para a existência deste facto. ${ }^{16}$ Sobre este aspecto, Webb (2003) refere que o surgimento da internacionalização de problemas sociais ${ }^{17}$ e a intervenção do Serviço Social sobre eles não valida, per si, o termo "Serviço Social internacional", por não haver evidências de convergência e padronização de práticas.

Perante essa aparente identidade colectiva e internacional fragilizada, outros desafios se impõem ao Serviço Social face ao processo de globalização. Historicamente, sabe-se que a questão social esteve na base da instituição das práticas dos assistentes sociais, que se baseavam numa luta de classes face à burguesia, então organizada, lutando pela justiça social, a equidade, a defesa dos direitos (civis, políticos e sociais) dos trabalhadores, passando a questão social a ser considerada como a expressão das desigualdades sociais. É no desenvolvimento dessa prática, em contexto de conflito social, que surgem as políticas sociais como instrumentos necessários para legitimar as conquistas da classe trabalhadora e, consequentemente, reduzir o conflito. O surgimento do Estado de Bem-Estar social, ligada à protecção social, permitiram a criação da base de sustentação funcional-ocupacional do Serviço Social (Montaño, 1997). Contudo, a nova questão social trazida pelas questões da globalização, caracterizada pela redução da força de trabalho, pelo desemprego estrutural ou pelo trabalho precário, e a minimização dos direitos sociais através da erosão do Estado Social, outrora conquistado, passa a ter novos contornos e significados para as políticas sociais e, consequentemente, para o Serviço Social (Faleiros, 1999, 2006; Montaño, 1997; Mouro, 2009; Noble, 2004). A orientação das

16. Midgley (2001) aponta vários estudos que indicam que a realidade de as escolas de Serviço Social não estão adequadas ao contextos internacionais. Esses estudos referem, também, que poucos assistentes sociais têm conhecimento sobre a realidade do desenvolvimento profissional de outros países, na medida em que a maioria está concentrada na realização de práticas locais, muitas vezes sem compreensão das influências globais. No plano da investigação é apontada a falta de estudos comparativos entre países. O autor releva ainda a ambiguidade da definição do conceito de "Serviço Social internacional", necessitando este, de ser resolvido.

17. Tais como o tráfico humano com fins de exploração laboral, a expansão da indústria do sexo, as migrações internacionais, os requerentes de asilo e refugiados, o fomento da adopção internacional, os conflitos culturais e o terrorismo. 
políticas sociais é, então, alterada. Por um lado, assiste-se à retirada, lentamente, das funções do Estado, passando a protecção social a ser, maioritariamente, do domínio da sociedade civil (IPSSs, ONGs, Igreja, famílias...). Contudo, o "sector social privado que, embora existindo e dando o seu contributo, não passou a oferecer as mesmas vantagens" (Mouro, 2009, p. 325). Por outro lado, a política social tornou-se focalizada, dirigindo-se, essencialmente, para os mais pobres, social e economicamente, transformando os serviços de princípios universalistas em serviços estatais dirigidos, essencialmente, para pobres (Montaño, 1997). Neste sentido, Faleiros (1999, p. 156) fala-nos de "desresponsabilidade social" por parte do Estado.

Face a todas essas transformações, o Serviço Social não é indiferente a esses contextos. Também ele tem sofrido transformações relevantes no que se refere à sua base de sustentação funcional-ocupacional e à sua importância nas sociedades contemporâneas. É no âmbito da privatização das políticas públicas que se observa a redução do campo de intervenção do Serviço Social e do redimensionamento das suas funções que tendem a confluir para uma "refilantropização do Serviço Social” (Iamamoto, 1996, p. 12; Montaño, 1997, p. 12). A prática descoordenada por parte dos assistentes sociais, que agora tendem a intervir, cada vez mais, em instituições privadas, aliada a uma política social fragmentada por parte dessas organizações, dificulta que as suas acções tenham repercussões em uma escala nacional (Montaño, 1997). Aponta-se, assim, que sob "uma máscara humanitária acompanhada de fortes apelos à solidariedade social" (Iamamoto, 1996, p. 12) por parte dos governos, ressurjam práticas caritativas e filantrópicas, correndo-se o risco de um retrocesso profissional às suas origens (Guerra, 2001).

Processos sociais macroscópicos, como a redução dos serviços sociais prestados pelos organismos públicos e a transferência do campo profissional de Serviço Social para o âmbito privado (Iamamoto, 1996; Montaño, 1997; Mouro, 2009); a desfragmentação dos paradigmas e valores clássicos de sustentação do Serviço Social; a redefinição das lógicas profissionais e sua reinterpretação dos conceitos de exclusão; o desenvolvimento de novas competências profissionais, especialmente na área da gestão e organização de equipamentos e coordenação de projectos sociais (Mouro, 2009); o surgimento de práticas burocráticas e managerialistas, pautadas pela eficiência e eficácia dos resultados, em detrimento das práticas relacionais e humanitárias (Amaro, 2009; Dominelli, 2004; Iamamoto, 1996; Mouro, 2009; Noble, 2004), e a forte dependência e 
substituição da intervenção profissional pelo exercício do voluntariado (Guerra, 2001; Noble, 2004) vieram permitir que o Serviço Social sofra, hoje, de uma "desprofissionalização" (Amaro, 2009; Dominelli, 2004; Iamamoto, 1996; Midgley, 2001), isto é, uma desqualificação profissional ${ }^{18}$ através da perda de controlo sobre o seu objecto de intervenção pelas constantes fragmentações sofridas ao longo do processo de globalização.

\subsection{Desafios e implicações para o Serviço Social: a necessidade de um reposicionamento profissional}

Para alguns pensadores (Faleiros, 1999; Midgley, 2001; Mouro, 2009), o Serviço Social encontra-se, hoje, desorganizado e com necessidade de se reposicionar e reordenar profissionalmente. Como refere Faleiros (1999), o Serviço Social necessita de uma "re-reconceptualização" semelhante à surgida nos anos 1960, no Brasil. Para Mouro (2009), a palavra utilizada, neste âmbito, é a de "modernização" do Serviço Social. Qualquer que seja o termo empregue, o problema parece estar associado à fragilidade de não consolidação da sua identidade profissional relativa ao seu passado e à dificuldade em, presentemente, olhar para a nova realidade social através de um reposicionamento que garanta o seu futuro profissional (Amaro, 2009; Mouro, 2009).

Atendendo a que o processo de globalização poderá ser considerado uma manifestação de correlação de forças e de poder, gerador de espaços de conflito, o Serviço Social deverá reposicionar-se, organizando e mobilizando a dimensão política da sua acção profissional, possuindo, para tal, sólidos conhecimentos de políticas públicas (Carey-Bélanger, 2001; Faleiros, 2006, p. 39). No entanto, Midgley (2001) considera que são poucos os assistentes sociais que se interessam e preocupam com o activismo social e político. Acrescenta, ainda, que alguns deles consideram-no inapropriado. Contudo, para Faleiros (1999) é

18. Guerra (2001, p. 288) refere que esta desqualificação profissional tem como base o crescimento do "Terceiro Sector" (IPSSs e ONGs), como executor da política social e onde nele o Serviço Social reordenou o seu campo de intervenção. O estabelecimento de uma variedade de vínculos de trabalho (flexíveis, a tempo parcial, com carga horária reduzida, contratação através de terceiros etc.) trouxe várias consequências aos assistentes sociais: "maior rotatividade dos profissionais, instabilidade, precarização das condições de trabalho, redução dos salários". 
necessário que o Serviço Social mobilize o poder e se implique, activamente, neste jogo de articulação de forças.

Os modelos tradicionais do Serviço Social que se baseiam no processo adaptativo dos sujeitos da sua intervenção às condições dominantes, como meio de manutenção da ordem social, poderão ser, hoje em dia, desajustados. Num contexto de forças hegemonicamente presentes, o Serviço Social deverá colocar ênfase nas relações sociais e de poder para combater a desigualdade, a injustiça, a opressão e defender os direitos sociais (Faleiros, 1999, 2006; Midgley, 2001).

Esta perspectiva possibilita que se fortaleça a cidadania, a autonomia e a identidade num processo dialético e complexo [...]. Esse processo implica garantia de direitos, desenvolvimento das condições básicas do sujeito e do próprio sujeito. É também uma articulação da dimensão política com a dimensão de serviços, não se reduzindo o Serviço Social, nem a relações psicológicas nem a relações burocráticas para acesso a determinados benefícios. (Faleiros, 1999, p. 169)

Como forma de se reposicionar e se colocar numa postura de movimento contra-hegemónico frente aos novos desafios, o Serviço Social deverá privilegiar essa dimensão política através de um investimento no conhecimento da realidade da nova questão social e dos processos que a geram. A investigação em Serviço Social torna-se, então, essencial na contemporaneidade (Guerra, 2001; Iamamoto, 1996; Montaño, 1997; Mouro, 2009). A legitimidade social do Serviço Social será expressivamente mais consistente na relação com a consolidação da sua vertente epistemológica, pois ela fará “[...] sugerir alternativas, explicar como pô-las em prática, num movimento em direcção à autonomia social e em direcção a um laço social reforçado com a população, e inscrever novas ideias em projectos concretos" (Carey-Bélanger, 2001, p. 309). É no desenvolvimento dessa vertente que se espera que a actuação sociopolítica do Serviço Social possa ser transformada.

Todavia, o Serviço Social parece pautar-se por uma fragilidade teórica e reflexiva, em consequência da insuficiente investigação e debate profissional (Amaro, 2009). Tal facto deixa crer que a sua acção profissional parece continuar a ser "produto de intuição, do instinto e/ou da experiência pessoal do profissional do que de referenciais teórico-metodológicos" (Guerra, 2001, p. 289). Na 
realidade, no novo contexto societário em que o Serviço Social se encontra é exigido aos profissionais competência teórica de qualidade necessária para conhecer, investigar, comentar, reflectir, decidir, avaliar e conceber propostas teórico-práticas e políticas que visem uma resposta consistente e eficaz às necessidades da sociedade contemporânea, implicando-se na defesa intransigente dos direitos, da justiça, da igualdade e da cidadania.

Para Montaño (1997), a investigação rigorosa dos fenómenos emergentes deverá estar aliada à formação reciclada e actualizada dos profissionais com vista ao desenvolvimento profissional pois, para Amaro (2009), os actuais traços de crise de identidade da profissão têm a sua origem na formação dada nas escolas e que, consequentemente, é repercutido à classe profissional.

Perante a diversidade de problemas complexos a que os assistentes sociais se confrontam no seu quotidiano profissional é, hoje, imperativo a apropriação de metodologias críticas exigentes que lhes permitam a produção de conhecimento que, por um lado, ajude na compreensão e interpretação desses problemas e possa contribuir para a capacitação dos assistentes sociais na dinamização de soluções - também elas cada vez mais complexas - e a responder, eficazmente, às problemáticas emergentes; por outro lado, conserte e consolide a identidade profissional, legitimando o seu status (Baptista, 2001) e, consequentemente, reconstrua e amplie os seus espaços de intervenção.

O Serviço Social contemporâneo, enquanto interventor nas relações de poder, implica o desenvolvimento de conhecimentos teóricos aliados a estratégias de intervenção no campo de forças hegemónicas versus contra-hegemónicas, sob valores globais de cidadania e democracia. A acção teórico-reflexiva, baseada numa ética global e em valores humanistas, deverão nortear o agir dos profissionais de Serviço Social, para que se consiga transformar o desenvolvimento económico e científico em desenvolvimento humano. A sua abordagem deverá ser orientada para práticas antiopressivas e antidiscriminatórias de qualquer natureza (Martins, 2003).

O grande desafio centra-se na urgência de um reposicionamento do Serviço Social edificado numa acção política, no sentido de se convocar sinergias que produzam um verdadeiro salto qualitativo de consciência humana e social. Este avanço de consciência leva-nos a querer substituir uma economia unidimensional por uma economia multidimensional, a sonhar com a globalização que tenha em consideração custos humanos "esquecidos" e capacidades huma- 
nas insuficientemente consideradas. Afinal, é necessário mirar o futuro para se reescrever o presente, acreditando sempre, de forma idealista, que esta visão possa, também ela, ser globalizada.

Recebido em 25/10/2011 - Aprovado em 4/4/2012

\section{Referências bibliográficas}

AMARO, Maria Inês. Identidades, incertezas e tarefas do Serviço Social contemporâneo. Locus Social, Lisboa, n. 2, p. 29-46, 2009.

. A civilização tecnológica, trabalho e os novos contextos de instabilidade 2005. (Texto policopiado.)

AREOSA, João. O risco no âmbito da teoria social. In: CONGRESSO PORTUGUÊS DE SOCIOLOGIA - MUNDOS SOCIAIS: SABERES E PRÁTICAS, 4., Lisboa: Universidade Nova de Lisboa, Faculdade de Ciências Sociais e Humanas, 2008.

BAPTISTA, Myriam. A investigação em serviço social. Lisboa/São Paulo: CPIHTS/Veras Editora, 2001.

BAUMAN, Zygmunt. Globalização: as consequências humanas. Rio de Janeiro: Jorge Zahar, 1999.

BECK, Ulrich. Risk society: towards a new modernity. Londres: Sage, 1992.

BRUM, Argemiro Luís; BEDIN, Gilmar António. Globalização e Desenvolvimento: Algumas reflexões sobre as transformações do mundo atual e suas implicações no processo de desenvolvimento. Desenvolvimento em Questão, Ijuí, v. 1, n. 2, p. 9-35, 2003.

CAMPBELL, Patricia; MacKINNON, Aran; STEVENS, Christy. An introduction to global studies. Chichester: Wiley-Blackwell, 2010.

CARAPINHEIRO, Graça. A globalização do risco social. In: SANTOS, Boaventura Sousa (Org.). Globalização: fatalidade ou utopia? Porto: Edições Afrontamento, 2005.

CAREY-BÉLANGER, Elaine. Políticas sociais e os trabalhadores sociais no contexto da globalização e da transformação do papel do estado: apelo a uma cidadania activa e a uma vitória à altura. In: MOURO, Helena; SIMÕES, Dulce (Orgs.). 100 anos de Serviço Social. Coimbra: Quarteto, 2001.

CASTEL, Robert. As metamorfoses da questão social: uma crônica do salário. Rio de Janeiro: Vozes, 1997. 
CASTELLS, Manuel. Information technology, globalization and social development. Genebra: United Nations Research Institute for Social Development, 1999.

CHOSSUDOVSKY, Michel. The globalization of poverty: impacts of IMF and world bank reforms. Londres: Zed Books, 1997.

COUTINHO, Maria. Racionalidade comunicativa e desenvolvimento humano em Jürgen Habermas: bases de um pensamento educacional. Lisboa: Edições Colibri, 2002.

DOMINELLI, Lena. Social work: theory and practice for a changing profession. Cambridge: Polity Press, 2004.

FALEIROS, Vicente. Os desafios do serviço social na era da globalização. Serviço Social \& Sociedade, São Paulo, v. 20, n. 61, p. 153-187, 1999.

. O serviço social no mundo contemporâneo. In: FREIRE, Lucia; FREIRE, Silene; CASTRO, Alba (Orgs.). Serviço social, politica social e trabalho. São Paulo: Cortez, 2006.

FOUCAULT, Michel. Truth and power. In: CALHOUN, Craig et al. (Orgs.). Contemporary sociological theory. Oxford: Blackwell, 1977.

. Subject and power. In: DREYFUSS, Hubert; RABINOW, Paul (Orgs.). Michel Foucault: beyond structuralism and hermeneutics. Chicago: The University of Chicago Press, 1982.

GARCIA, José Luís. A crítica política da tecnologia como tarefa da sociologia contemporânea. Trajectos — revista de Comunicação, Cultura e Educação, Lisboa, n. 2, p. 75-81, 2003.

GIDDENS, Anthony. O mundo na era da globalização. Lisboa: Editorial Presença, 2006.

GRANJO, Paulo. Quando o conceito de "risco" se torna perigoso. Análise Social, Lisboa, v. XII, n. 181, p. 1167-1179, 2006.

GUERRA, Yolanda. As racionalidades do capitalismo e o serviço social. In: MOURO, Helena; SIMÕES, Dulce (Orgs.). 100 anos de Serviço Social. Coimbra: Quarteto, 2001.

HABERMAS, Jürgen. Técnica e ciência como “ideologia”. Lisboa: Edições 70, 2009.

HESPANHA, Pedro; CARAPINHEIRO, Graça. A globalização do risco social: Uma introdução. In: (Orgs.). Risco social e incerteza: pode o estado social recuar mais? Porto: Edições Afrontamento, 2001.

IAMAMOTO, Marilda. O Serviço Social na contemporaneidade: os fundamentos teórico-metodológicos e técnico-operativos do trabalho profissional. In: GIL, António (Org.). Metodologias e técnicas do serviço social. Brasília: CNI/Sesi, 1996.

IOM - INTERNATIONAL ORGANIZATION OF MIGRATION. World Migration Report 2010 - The future of migration: building capacities for change. Genebra: International Organization for Migration, 2010. 
JERÓNIMO, Helena. A peritagem científica perante o risco e as incertezas. Análise Social, Lisboa, v. XLI, n. 181, p. 1143-1165, 2006.

LORENZ, Walter. Social work and new social order: Challenging neo-liberalism's erosion of solidarity. Social Work \& Society, Essen, v. 3, n. 1, p. 93-101, 2005.

MARTINS, Alcina. Investigação em serviço social: perspectivas actuais. In: Serviço Social: Unidade na diversidade. Encontro com a Identidade Profissional. Actas do I Congresso Nacional de Serviço Social. Lisboa: APSS, p. 50-59, 2003.

MARTINS, Hermínio; GARCIA, José Luís. Introdução. Análise Social, Lisboa, n. 181, p. 941-956, 2006.

MIDGLEY, James. Issues in international social work: resolving critical debats in the profession. Journal of Social Work, Londres/Thousand Oaks, CA/New Delhi, v. 1, n. 1, p. 21-35, 2001. Disponível em: <http://www.sagepub.com/jimenezstudy/articles/Midgley.pdf $>$.

MONTAÑO, Carlos. O Serviço Social frente ao neoliberalismo: mudanças na sua base de sustentação funcional-ocupacional. Serviço Social \& Sociedade, São Paulo, n. 53, 1997.

MOURO, Helena. Modernização do serviço social: da sociedade industrial à sociedade do risco. Coimbra: Almedina, 2009.

NOBLE, Carolyn. Postmodern thinking: where is it taking social work? Journal of Social Work, v. 4, n. 3, p. 289-304, 2004.

PAUGAM, Serge. A desqualificação social: ensaios sobre a nova pobreza. Porto: Porto Editora, 2003.

PAYNE, Malcolm; ASKELAND, Gurid. Globalization and international social work: postmodern change and challenge. Burlington (EUA): Ashgate, 2008.

PNUD. United Nations Development Programme. Human Development Report 1999. Globalization with a human face. Nova York: Oxford University Press, 1999.

. Human Development Report 2001. Making new technologies work for human development. Nova York: Oxford University Press, 2001.

. Human Development Report $2010-20^{\text {th }}$ anniversary edition. The real wealth of nations: pathways to human development. Nova York: United Nations Development Programme, 2010.

ROSANVALLON, P. La nouvelle question sociale: repenser l'état-providence. Paris : Seuil, 1995.

SANTOS, Boaventura Sousa. Os processos da globalização. In: (Org.). Globalização: fatalidade ou utopia? Porto: Edições Afrontamento, 2005.

SCHOLTE, Jan. Globalization: a critical introduction. Nova York: Palgrave, 2000. 
SILVA, Luísa. Modernidade e desigualdades sociais. Lisboa: Universidade Aberta, 2008.

STEGER, Manfred. A globalização. Santa Maria da Feira: Quasi Edições, 2006.

WARNIER, Jean-Pierre. A mundialização da cultura. Lisboa: Editorial Notícias, 2002.

WEBB, Stephen. Local orders and global chaos in social work. European Journal of Social Work, Newcastle (Austrália), v. 6, n. 2, p. 191-204, 2003.

WINNER, Langdon. Duas visões da civilização tecnológica. In: MARTINS, Hermínio; GARCIA, José Luís (Orgs.). Dilemas da civilização tecnológica. Lisboa: Instituto de Ciências Sociais da Universidade de Lisboa, 2003.

WORLD BANK. The World Bank Annual Report 2010: year in review. Washinghton: The World Bank, 2010.

YÁÑEZ, Clemente. Globalização e localismo: Novas oportunidades para o desenvolvimento. Análise Social, Lisboa, v. XXXII, n. 143-144, p. 901-912, 1997. 